\title{
Understanding High School Students' Sports Participation
}

\author{
Students of So285 Section 1, Fall 2014 • Angela Cora GARCIA ${ }^{2}$
}

Tn this paper we conducted a qualitative analysis of twenty-eight

1 semi-structured interviews of college students. Interviewees were asked about their high school experiences with sports in order to discover the main factors leading to positive or negative experiences. We found that the influence of family and friends and the opportunity to participate in a competitive activity were the two most important positive aspects of students' high school sports experiences. The most prevalent negative aspect of high school sports participation was a problematic experience with a coach. While both friends and family influenced students' decisions to initiate and maintain participation in sports while in high school, family influence was much stronger than the influence of friends. Given the need to expand physical fitness on a national and global level, greater understanding of the factors impacting sports participation will be useful to a wide range of stakeholders, including students, teachers and educational institutions, and policy makers.

Keywords: sports participation, high school coaching, family influence, friendship influence, team sports

\footnotetext{
${ }^{1}$ Student co-authors, listed alphabetically: Ryan Aberdale, Stephania Adondakis, Nigel Allard, Obinna Aribeana, Martin Bannerman, Alejandra Borge, Christopher Cameron, David Campagna, Lanny Chung, William Coughlan, Nicole Derba, Wesley Dow, Tamzin Ellerbeck, Thomas Fitzpatrick, Charles Goodwin, Jeffrey Hill, Christiana Hynds, Andie Keegan, Keagan Latta, Leah Lubert, Steven Maffiolini, Christopher Malonis, William Patton, Daniel Reardon, Connor Root, Erin Shannon, Kevin Sornoza, A. Vay Su, Jesse Wilde, Ricky Yu

${ }^{2}$ Department of Sociology/Department of Global Studies, Bentley University, Waltham, MA, USA
} 


\section{Introduction}

High school students' sports participation has long been considered a positive aspect of their secondary school experience. In spite of occasional problems or possible negative effects on some student's academic performance (e.g., Harris, 2014), there are many benefits of high school sports participation for students (e.g., Bailey, 2006; Marsh \& Kleitman, 2003; Shulman \& Bowen, 2001). For example, previous research on youth sport participation has identified a number of ways in which students' experiences in sport can have beneficial effects for them, including learning life skills (e.g., Holt et al., 2008) or improving academic performance (e.g., DeMeulenaere, 2010). There are a range of studies which examine how coaching can create positive benefits for student athletes. Holt et al. (2008) found that coaches can be a positive influence not just on the youth's sports performance but in terms of personal development and learning life lessons. Ahlberg, Mallett and Tinning (2008) investigate how coaching can increase student athlete's motivation and autonomy. Lacroix, Camiré and Trudel (2008) found that effective coaching can better help students develop as athletes.

Most of the previous research on the sport participation of high school students focuses on the academic, health, or educational benefits of participation. The current paper addresses a related issue, the student athletes' perceptions of the value and challenges of the experience of participating in high school sports. In addition, we explore the factors that influence students' initiation and maintenance of high school sports participation.

Previous research on sports participation focuses on a variety of issues relevant to our project. For example, Kondrič et al. (2013, p. 10) found that there were six main factors that affected students' sports participation: "sport action with friends, popularity, fitness and health, social status, sport events and relaxation through sports." Russell and Limle (2013) found that people who specialized in a sport as youths were less likely to participate in sports as young adults. This suggests that there is a funneling effect for those who overparticipate at a young age (see also Crane and Temple [2015] on why youth drop out of organized sport). Excessive participation in organized youth sports may be too much of a good thing.

Parents of children participating in youth sports have considerable influence over their child's experience (Coakley, 2006). Knight \& Holt (2014) have shown that parents often have a positive influence, when appropriate parenting approaches are used. They found that parenting efforts are most effective when they are consistent with the student's goals and a positive "emotional climate." Hassandra, Goudas and Chroni (2003) found that both peers and 
parents contributed to a student's motivation to participate in physical education. Previous research on how youth sport participants are motivated to participate found that peers were as important as adults in creating a "motivational climate" (Vazou, Ntoumanis \& Duda, 2005). Pummell, Harwood and Lavallee (2007) found that parents and peers were also important in helping young athletes make the transition from lower to more elite levels of competition.

While a number of previous studies have explored factors affecting sports participation, there has not yet been an explorative qualitative study of how high school student athletes perceive their sports participation. In the remainder of this paper we will first describe our data, methods, and theoretical perspective, and then describe our research findings about the factors influencing students' high school sports participation.

\section{Data, methods, and theoretical perspective}

We use a symbolic interactionist perspective because it focuses our attention on students' experiences and how their perspective on those experiences is related to their decisions regarding sports participation (e.g., see Blumer, 1969; 1992). Briefly, Blumer's perspective on symbolic interactionism is that individuals' beliefs and interpretations of their situation and the actions of others shape their decision-making and their actions through a self-reflective process. Blumer writes:

"[H] uman beings interpret or "define" each other's actions instead of merely reacting to each other's actions." (Blumer, 1992, p. 24)

"Whatever the action in which he is engaged, the human individual proceeds by pointing out to himself the divergent things which have to be taken into account in the course of his action. He has to note what he wants to do and how he is to do it; he has to point out to himself the various conditions which may be instrumental to his action and those which may obstruct his action; he has to take account of the demands, the expectations, the prohibitions, and the threats as they may arise in the situation in which he is acting... The human individual pieces together and guides his action by taking account of different things and interpreting their significance for his prospective action." (Blumer, 1992, p. 26)

We analyzed the data using a simplified version of the coding approach developed by practitioners of grounded theory (e.g., Charmaz, 2003; 2004; Glaser \& Strauss, 1967; see also Morse, 1994). We used a semi-structured interview approach to design the interview guide and conduct the interviews (e.g., Rubin \& Rubin, 2005; see also Berg 1989). 
Each student co-author conducted one interview, audiotaped it, and transcribed it. The instructor then checked the transcript of each interview against the audio tape, and had the students enter the corrections into the transcripts. The transcripts were shared with all members of the course who collaboratively conducted the qualitative analysis of the data by studying the transcripts, collating the raw data for tabulations, and selecting a range of illustrative quotes for each theme. We made group decisions about how to categorize and interpret the data in the transcripts. The student co-authors produced a rough draft of the manuscript during the course, and the instructor edited and revised the paper after the course was completed.

This research project was submitted to the "Suburban University" Institutional Review Board and received approval as an "exempt" project. Each interviewee signed a consent form prior to participating in the interview. In order to protect the privacy of the research subjects, first names only were used in the interviews, and these names were changed to pseudonyms in the transcripts of the interviews.

The interviewees were all undergraduate students at "Suburban University", a small private university in the greater Boston area. It is a selective institution which attracts highly motivated students. There is some degree of ethnic, cultural, and national diversity on campus (about sixteen percent of the student body are foreign students, and about seven percent are from American minority groups). However, there is less economic diversity; most of the students are from relatively well-to-do families.

Students who were currently taking the "Sociology of Sports" course were not included in the sample, in order to avoid having interviewees who were too familiar with the issues we were studying. The data analyzed in this paper are part of a larger project which includes the experiences of interviewees' participation in college sports as well. All of the students interviewed participated in sports in high school.

In total, twenty eight undergraduates were interviewed about their participation in sports while in high school. As Table 1 shows, $71 \%$ of the interviewees were seniors, $11 \%$ juniors, and $18 \%$ sophomores. This distribution likely occurred because most students asked fellow students who were friends or acquaintances to be interviewed. Since almost all of the students in the class were seniors, this tilted the balance toward seniors.

The student population at Suburban University is approximately $60 \%$ male. We aimed for a roughly equivalent distribution of males and females in the 
sample. There were 19 males and 9 females in the sample (only $32 \%$ of the subjects were female). All of the students interviewed were at least 18 years old.

Table 1

Research subjects

\begin{tabular}{lccc}
\hline \multicolumn{1}{c}{ Year in school } & Male & Female & Totals \\
\hline Sophomore & 3 & 2 & $5(18 \%)$ \\
Junior & 1 & 2 & $3(11 \%)$ \\
Senior & 15 & 5 & $20(71 \%)$ \\
\hline Totals & $19(68 \%)$ & $9(32 \%)$ & $28(100 \%)$ \\
\hline
\end{tabular}

We formulated the interview guide as a group and included questions about participation in high school sports, experiences playing sports in high school, influences on playing sports in high school, and the effect of the coach in high school sports. The relevant parts of the interview guide are in the appendix. We begin the discussion of our findings with the interviewee's experiences with sports participation at the high school level, the positive and negative aspects of their experiences with high school sports, and the influence of friends, families, and coaches on their participation.

\section{Commitment of time and effort to high school sports}

Twenty-seven of the twenty-eight students interviewed participated in at least one varsity sport in high school, the remaining student participated only on a junior varsity team rather than a varsity team. A number of the students participated in more than one sport. The students in our sample participated in a wide variety of sports while in high school. The most common varsity sports were (in order of frequency) track and field, football, basketball, lacrosse, soccer, baseball, hockey, softball, and field hockey.

Most of the interviewees in our sample were serious athletes while in high school who had made a major commitment to their main sport for a number of years. More than half (15 out of the 28 ) of the interviewees participated in their main sport for ten or more years from childhood to graduation from high school. 


\section{Positive aspects of high school sports participation}

The interviewees were asked about their positive and negative experiences in high school sports (see Table 2). The two most frequently mentioned positive aspects were their friendships with other team members and the competitiveness of the individual or their team. The third most common experience mentioned was the response of the fans and the excitement of performing in public. The fourth most frequently mentioned positive experience was being on a team. Love of the sport was only mentioned by five students, and usually in passing rather than as an articulation of their favorite aspect of their high school sports participation.

Table 2

Positive aspects of high school sports participation

\begin{tabular}{lc}
\hline Positive aspects & Number of students mentioning \\
\hline Friendships & 19 \\
Competitiveness/Quality & 18 \\
Fans/Excitement of performing in public & 8 \\
Team experience & 6 \\
Love of the sport & 5 \\
\hline
\end{tabular}

Friends. Nineteen of the twenty eight interviewees mentioned the friendships they made through sports as one of their favorite aspects of their high school sports participation. At the high school level, student athletes create strong bonds with their teammates and these bonds are characterized by strong friendships both on and off the field. The interviewees explained how high school sports either let them play with old friends, make new friends or strengthen existing friendships throughout the course of high school:

"I would definitely say the memories and the friendships. Basically I was friends... best friends with everyone on my team, all eleven of my teammates, so we basically grew up together and it was just the memories that we built through basketball" (Kurt, Interview \#8).

"I think playing with kids that you grew up with was a big part of what I liked. For football... I like how when you're on a team with 80 to 100 guys, you form a great friendship with all of them.” (Eric, Interview \#18) 
"I'd say a really positive thing was the amount of friends I made doing track and field. I recently moved from Arizona to California, so you know I didn't have many friends, but when I joined track and field there were a lot of people of all different genders and grades." (Joseph, Interview \#5)

Even if the student's team was not as good as their competition, the interviewees still valued the friendships they formed from the sport. For these individuals it was not team success but the comradery and friendships they built that influenced their desire to participate in the sport. Matt stated that his "team was always really bad." Nevertheless, he cherished the friendships he formed:

"Even though we were losing a lot...just like getting to play sports with your friends, like kids that you grew up with since elementary school and it's just like when you're out there, even though our team wasn't as good as others, it was still fun hanging out with your buddies and playing a sport that you like." (Matt, Interview \#12).

The major role of friendships in the interviewees' high school sports experience is not surprising, given that relationships with peers is very important in the life of high school students in general.

Competitiveness. The competitive nature of the experience is another aspect of high school sports that was frequently mentioned as a positive factor. For the student athletes in our sample, it was essentially equally important to friendships in terms of the number of interviewees who mentioned it. Their interest in and enjoyment of competition may be something that distinguishes these student athletes from non-athlete high school students. By competition we refer to either the excitement of trying to win a game, the success of one's team, or pride in one's own skill and accomplishments when playing that enabled one to contribute to the team's success. For example, Arthur enjoyed the fact that his high school team was very good. He found that the success of his team was one of his favorite parts of his high school sports participation:

"I really enjoyed the fact that we were really good in high school. I mean we went 8-0 my freshman year... I consider myself an extremely competitive person.” (Arthur, Interview \#15).

Sally and Ralph also enjoyed the success and quality of their teams:

"Since [soccer] was the best sport at my school it was kind of an added bonus just to play for a team that was so good and we were so good." (Sally, Interview \#9). 
"We were very successful in high school in both baseball and football, also track. It was a very proud feeling to come out of games and playoffs with great team wins and doing well against the competition." (Ralph, Interview \#25).

A number of other interviewees touched on the importance of winning when competing against others:

"I hate loosing so I say overall sports have made me very competitive. I don’t like loosing anything." (Greg, Interview \#27)

"I myself am an extremely competitive guy when I'm playing anything. It doesn't matter how big or small the event may be, whether it be a drill in the beginning of practice or a tournament. I am extremely competitive across all bounds. I really liked the intensity and the coaches and players demanded the best from me." (Nate, Interview \#10)

"I am very competitive when I play sports and am pretty competitive in general. I like to keep playing sports to get rid of some of that competitive energy." (Jenny, Interview \#19).

"I had a lot of really good game moments, I guess you could say in high school and the recognition that I was getting was something that I was very proud of." (Penny, Interview \#7).

Fans and performing in public. The third most common response to the question about favorite parts of the student's high school sports participation was the excitement of performing in public and the response of the fans. The positive reinforcement that comes from a crowd supporting one's team makes the participant feel as though his or her contribution really matters. Mark describes how he loves the thrill of making the big play in a game and playing in front of large crowds:

"The fans were fun. Well football and hockey were our two biggest sports. It's always fun being in front of a big crowd, big game, and shining in the moment is fun. I don't know you just get that rush when everyone is freaking out when after you do something well, and you're pretty happy about it... That's fun." (Mark, Interview \#2).

Penny also appreciates the excitement and attention she gets from being on a successful team: 
"I would say the overall school spirit, having so many people coming to your games and being looked up to by under classmen and being remembered for what you did. The feeling of being best in the state at something and you're respected for it." (Penny, Interview \#7).

"You just get to represent your school, so it's always fun to go out and work hard and have teachers and students and classmates, and people around town saying "Hey good game." I remember after my Thanksgiving game, I went to the grocery store and someone was like "Oh, you're number 38; great job!" He knew who I was. So I always thought that was really cool." (Kevin, Interview \#26).

Team Experience. The fourth most common positive aspect of high school sports mentioned was the experience of belonging to a team. Being on a team can involve a broad range of experiences, and the individuals interviewed valued different aspects of the team experience. Jane's perspective on her team experience focused on its facilitation of connections with others:

"You really got to know a small sect of people that you really could bond with because you had more in common than just 'Oh, we're in the same class.” (Jane, Interview \#3).

Similarly, Pete said:

"Probably just being on a team because after games we'd have PAWs, Party After Wins, where we'd get pizza and play video games, and that was a real fun time and I'm still friends with the people that I played with in high school." (Pete, Interview \#1).

After Pete's team won a game they would come together and celebrate the victory. He enjoyed winning as a team and even more so enjoyed celebrating with his team members afterwards. He also notes that the teammates he would celebrate with are still some of his close friends today.

Being part of a team is different from an individual sport experience because you are not just looking out for yourself. You are part of something much bigger than yourself, so you and your teammates must work together to achieve the team's goals:

"A huge positive for me was just like learning to work as a team like in football, literally nothing gets done unless everyone is on the same page." (Matt, Interview \#12). 
Being on a team not only helped these students in sports but also taught them important life lessons:

"I think I enjoyed definitely being part of a team and having an organized activity after school every day, I also felt like it definitely helped me with my school work too, just always having a routine and getting my exercise in right after school, was also great." (Anne, Interview \#16).

Love of the Sport. Only five interviewees mentioned "love of the sport" as something that made them enjoy their high school sports participation. Carl mentions that basketball is " a great game to play"; and Sally says that "I obviously love soccer." Note that Tom's mention of his love for the sport is only mentioned in conjunction with his description of the friendships that he formed:

"I think I enjoyed making new friends and being with the team and kind of making friendships while playing in a sport that we grew up loving." (Tom, Interview \#4).

While most of these students clearly enjoyed playing the game, love of the sport was not the main reason they played.

Summary. In sum, even though these students enjoyed their high school sports participation for a variety of reasons, the friendships formed and the competitive aspects of the activity are clearly the most important aspects for most of our interviewees. Friendships with their team mates are deeply connected with some of the other positive experiences the interviewees described, such as the experience of belonging to a team. Some interviewees even mentioned that they are still good friends with former teammates from high school today, while love of the sport was only occasionally mentioned.

\section{Negative aspects of high school sports participation}

While our interviewees were largely positive about their experiences with sports in high school, we also asked them to discuss any negative aspects. The biggest surprise in our research findings is the prevalence of negative experiences with coaches during participation in high school sports. The other two most common negative experiences reported were the effect of injuries or the time pressures sports participation puts on athletes. Balancing academic and other responsibilities and activities with sports participation was a challenge for some students. 
Table 3

Negative experiences participating in this sport

\section{Types of negative experiences}

Problems with coaching

Injuries

Conflicts with other responsibilities
Numbers of times mentioned

19

9

9

Coaching. The students who mentioned positive experiences with coaches described them with terms such as "helpful", "supportive", or having a "good coaching style." Some students also characterized their coach as being a good mentor or role model. Mark had positive and negative experiences with coaches. Here he describes one of his better coaches:

"My high school coach that I had from freshman to junior year he also ran the summer camp when I was in middle school so I knew him pretty well. I actually broke my arm during summer camp, and he helped me with that. He kind of just mentored me because he knew I had potential, so he always gave me those opportunities, and he helped me grow as a player, and over the three years we got closer and closer, and junior year we lost two of our captains due to injuries so he gave the spot to me. We also just talked about other personal stuff, not just sports but then he left to go be a scout for college." (Mark, Interview \#2).

Unfortunately, 19 of the 28 students interviewed stated that they had problems with a coach while participating in sports at the high school level. For those who had negative experiences with coaches there were a range of issues that disturbed the students. Mark was very unhappy with his senior year coach who had a punitive approach:

"But then my senior year coach was just miserable absolutely miserable... He made me absolutely hate the sport, he absolutely burnt me out. Coming into the year we were predicted to go to states. We had a lot of talent on our team senior year, junior year too, but his coaching style and how he ran the team was miserable and made no sense. $\mathrm{He}$ would punish people for doing the right things, reverse psychology, but it didn't work. The whole team got pissed at each other. It was just a messy situation.” (Mark, Interview \#2). 
Pete mentioned that one of his coaches was a "jerk", and another "didn't know what he was doing" (Interview \# 1, "Pete"). Joseph also had a negative experience with a coach. He questioned her interest in the team as well as her competence to coach the sport:

"My coach, honestly I don't really remember my coach's name. That's how unattached she was to us. She just like, made us run laps and then she left. So, I don't, I mean, overall I knew a coach, I played other sports in middle school where there were real coaches. This lady was not a real coach and you know, it's just. To me, I think that, she just took it for the money and she left when she could. So it was pretty overall negative, highly negative experience because she just was not there for me. She wasn't there for the team, she didn't teach me anything. She didn't encourage us. Apparently she was a good triple jumper in college or whatever but she never showed us anything. So you know, as a leader and as a coach, you are supposed to lead by example. And you are supposed to encourage the team to do the same, but she just did not do that and I don't respect people like that." (“Joseph", Interview 5)

For others, the issue was a clash of personalities or personal dislike:

"I would say I didn't like my basketball coach, and it made me not enjoy the sport as much or the season itself." ("Tom", Interview \# 4)

"My high school coach, I never felt as though I could get along with my high school coach. I always felt our personalities clashed. I never felt comfortable around here. I think because of this, after my senior year in high school, I kind of just wanted to be done with softball, which I was." ("Kim", Interview \# 20)

Others critiqued coaches for favoritism:

"For football, I guess, just basically if you got on his good side you would play, but other than that we didn't really like him. As for basketball [coach], we didn't like each other." (“Carl”, Interview \# 6)

Another interviewee described the challenges when there was too much coach turnover:

"I had a couple of different coaches which was tough because there wasn't much continuity from year to year so kind of managing those different expectations and knowing what different coaches wanted out of me was difficult." ("Pete", Interview \# 1) 
In Pete's situation there were just too many coaching changes which can be hard on an athlete. Having to start a new relationship with a new coach multiple times can be stressful.

A bad experience with a coach can prompt a student to leave a sport:

"I had a negative experience with the coaching staff which is why I stopped playing." (Interview \# 3, "Jane")

Overall, our results suggest several main issues that were likely to occur in problematic relationships with coaches. These were a punitive coaching style, lack of competence, lack of interest in the students, favoritism, personality conflicts, and frequent coach turnover. These results suggest that if high schools can provide coaches with better teaching and mentoring skills and techniques, the student athlete's experience of participating in the sport will be more enjoyable and more useful to them.

Conflicts with other responsibilities. Some interviewees indicated that high school sports took their attention away from other important responsibilities or activities. Nine interviewees reported negative experiences due to time conflicts with other responsibilities. One interviewee said "maybe not focusing in... high school as in academics during game day that probably wouldn't be a good thing." (Kurt, Interview \#8); "I realized I had to learn to manage my time better" (Tom, Interview \#4); “During football my grades weren't that good but after I stopped playing my grades improved immensely... it took up a lot of free time that I could of done school work in.” (Arthur, Interview \#15). In sum, time conflicts seemed to be managed well by most of the students, but some found this aspect of their sports participation challenging.

Injuries. Nine out of the twenty-eight interviewees reported negative experiences due to injuries they sustained while participating in sports. Matt, a former football player who experienced this problem said "I've had a lot of injuries so that's obviously something I wish I could have avoided." (Matt, Interview \#12). Kurt responded "Maybe some negative experiences would be injuries." (Kurt, Interview \#8, lines 28-32). Some other interviewees also had negative experiences with injuries, which had long term consequences:

"A lot of times you are banged up while playing. During the season you're never really fully healthy." (Eric, Interview \#18)

"I did suffer some injuries playing sports that I will probably have to deal with for the rest of my life." (Bill, Interview \#28). 
While definitely a negative experience, injuries were not mentioned by most of the interviewees. It seems that the problems with coaches were more important in their minds than the experience or risk of injuries.

Summary. In sum, the influence of coaches is a major factor affecting students' experience with sports in high school. The students' relationship with their coach affects their enjoyment of the activity and how much they learn from it. While most students continued with their sports participation in spite of negative experiences with coaches, some students did leave a sport because of such an experience. Although sports may have caused some other types of problems as well, such as injuries or being less focused on academics or other responsibilities, the positives seem to outweigh the negatives for most students.

\section{Influence of family on high school sports participation}

When it comes to a student's decision to participate in sports while in high school, we found that family and friends were the major influences encouraging students in this direction. Both play a large role in influencing participation in sports throughout the student's life, up to and including high school. However, in our data the role of the family was clearly more important than friendship. Twenty-six of the 28 interviewees reported family influence of some kind on their sports participation. Only two of the interviewees said their parents did not influence them to participate in sport. One family was not involved, and the other family actively discouraged sports participation in favor of a focus on academics. The influence of friends was also important, with 18 of the 28 interviewees reporting that friends influenced them to participate in high school sports.

We found that there were several ways in which family had an impact on students' sports participation in high school. First, parents provided financial, emotional and practical support to student athletes, and devoted time and effort to facilitating their child's participation in sports. Second, parents and other family members served as role models, for example by setting an example as a former athlete, or by serving as a coach for their child's team. Third, parents expressed concern for their child's welfare and safety; for some parents this meant limiting or forbidding certain types of sports participation.

Family support and involvement. For most students, their parents were the most important source of family influence on their sport participation. The most frequently mentioned type of family influence was parental support and involvement. For some families, this meant exposing their child to sports and investing time and money in facilitating their participation: 
"I pretty much played every sport in middle school, they signed me up for T-ball, basketball, soccer... karate. That went well. Um I think they kind of just wanted to give me exposure to every sport to see if any I had actual interest in." (Lee, Interview \#14)

Jane reports a similar experience:

"Well, my parents encouraged me to play sports and signed me up for different things, my neighbors were really involved in sports, almost all the kids in our town did sports, my brother played." (Jane, Interview \#3)

"My parents were extremely supportive of me, like I said I began playing when I was 4 . At that time they had to drive me every single day. When I was 6 my dad was the coach. As I got older I began travel soccer which required a lot of cash expenses traveling to Florida, Arizona. Have to pay the club as well to play on their team for coaches' salaries and equipment. Parents have always been extremely supportive of me both financial and time invested. To this day they try to watch as many games as they can. They'll watch live updates of games, and texting me after games, asking about goals and red cards etc." (Nate, Interview \#10).

By contributing financially, traveling to these sporting events and actually becoming a coach, these parents influenced their son to keep participating in the sport.

Parents usually want only the best for their children and will often encourage them to play sports for a variety of reasons. For example, Penny's father believed that playing a high school sport was a good way to learn how to work with people, and was not just about simply playing a sport. She said:

"[My father] always encouraged me to play sports because of all things you can learn from them besides just the sports related. The life lessons like teamwork and figuring out how to deal with people really come from sports." (Penny, Interview \#7).

"My Dad coached me on several different teams until I got to high school. Every summer, I had to play on a tournament team so we would travel around New England almost every weekend of the summer... My dad was absolutely my biggest influence that I had I guess.” (Kim, Interview \#20). 
"Playing sports my parents really pushed it upon me, I think it was something that they wanted me to pursue not only to keep me out of trouble but to keep me in shape and also it was just good to be active. They definitely pushed that upon me, they wanted to teach me about winning and losing, trying hard and dealing with adversity." (Bill, Interview \#28)

Role models. Family members who were athletes when younger also influenced their children by acting as role models. This type of direct parental influence may even be experienced as pressure by children who grew up in a family with a parent who had been a successful athlete. Often, a student choose to play a certain sport because someone very close to them played that same sport and they want to follow in their footsteps. For example, Carl stated in his interview,

"My dad played football so I guess he somewhat pushed me in that direction." (Carl, Interview \#6).

"Both of [my parents] were athletes growing up, so they definitely pushed me in that direction." (Cory, Interview \#17).

"By far my father- he played college football and was an all - American and got scouted to the NFL and couldn't play because of his knee." (Penny, Interview \#7).

"I would say my mom, she influenced me the most... she didn't lose a high school varsity game in all of her career for basketball so I definitely had some shoes to fill and yeah I think she just brought me up that way and I just fell in love with the game." (Kurt, Interview \#8).

These students' parents were role models for them, and gave them one more reason to keep playing the sport in high school. Another way parents can be role models is by volunteering as a coach for their child's sport.

Siblings. These student athletes were also sometimes influenced by a sibling who plays sports. If your sibling excelled at a sport in high school, others may expect that you will do the same. Interviewees seemed to be motivated to compete with older siblings and to try to be like them:

"My older brother had played basketball for four years and he was a captain so I definitely wanted to be like him, because he was my older brother, so that was probably the biggest thing that impacted me." (Pete, Interview \#1). 
"I want to say may be my brother. He was the first one in my family to start playing football and I always went to his games and watched him and when I started playing he was always giving me tips and pointers and really helped me get up to speed with the other kids who played Pop Warner, which I never did." (Matt, Interview \#12).

"The biggest influence was my sister. She began playing soccer when she was 5 and started playing basketball when she was 6... All the way through high school my sister was playing sports. She was the starting center her freshman year. She really inspired me to become the best athlete that I could be. I consistently trained against her. She's older than me, but once I got to my teenage years I started to outpace her physically and that really frustrated her because she had always been able to muscle me up a little bit. So there was a great rivalry between the two of us, to be the best athlete, to be the stronger, faster one. She really inspired me to be the best I could be.” (Nate, Interview \#10).

Concern for student's welfare. For the interviewees whose parents expressed concern for their child's welfare, the parent typically limited the students' participation when they perceived excessive risk of injury. Parents who viewed a sport as too violent might keep their child from playing that sport or ask them to wait until they are older and more capable of handling it.

"For a while they never wanted me to play football, but I kept pushing them and finally they gave in when I went to high school." (Tom, Interview \#4).

"I would say that both my father and my mother keep telling me just every time focus on academics and not sports. In specific my mother didn't even like the fact that I played soccer. She didn't like the fact that I had to spend so much time practicing, and probably also coaching-wise maybe. Maybe she was like afraid I could get hurt, something like that." (Frank, Interview \#23).

"Well, the whole reason I never played Pop Warner was because my mom and dad had a rule within my family that wouldn't allow us to play football until high school because they didn't want us to get hurt playing a physical sport like football.” (Matt, Interview \#12).

However, not all families tried to counsel their children out of high risk sports. One family pressured their son continue to play sports in college despite a series of injuries: 
"My family is so mad at me for not continuing playing in college it is absurd. They were so mad. Which I get it, because that was what my whole plan was, and I was set on that from day one. But I just got burnt out senior year, and the injuries caught up to me... but my family always loved going, they were always at every high school game. My dad would end up driving to most premier games. When I got my license I would tell him to stay home and have some free time for once, but they were pretty much at every single game." (Mark, Interview \#2).

\section{Influence of friends on high school sports participation}

Friends were also an important influence for the students in our data set. About two thirds of the interviewees said that their friends influenced their participation in high school athletics.

"My friends definitely made me want to play sports. I didn't really, even like lacrosse but I played because some of my best friends played." (Tom, Interview \#4).

"Well, all of my friends played so of course I wanted to play." (Lee, Interview \#14).

"My friends wanted me to play football with them because they were playing it." (Eric, Interview \#18).

For a couple interviewees, friends had no influence on their decision to participate in a sport:

“No, my friends didn't have anything to do with it. It was a separate thing, and my social network had nothing to do with it either." (Cathy, Interview \#21).

For Mark, friends were also not really an influence for his participation. The fact that his group of friends played the sport made it more enjoyable, but they were not the main reason why he was playing the sport. However, even for him the social relationships were a key factor:

"I didn't start playing because of my friends because I was playing before them. But my closest friends did play sports with me. Most of the kids I still talk to today from high school were on a hockey team with me at some point. Most of the kids I hung out with were on my teams just because you are traveling around with them half the time with them 
anyway, and you see them at school you are going to talk to them about the game. If not, a lot of kids I played with were from other towns and weekends I would hang out with them; meet a different person, that's the beauty of playing games all over the place. You meet a ton of people. In showcases especially Florida, and all the other places we would fly for the weekend." (Mark, Interview \#2).

Sports provide an opportunity for social interaction on a sustained basis. Students who have a good group of friends playing the sport with them may be more likely to want to continue to play the sport.

Summary. In sum, as the interviewees remembered their high school sports experiences, they felt that friends were an important influence on their sports participation. However, family influence was even greater, with parents being supportive in a variety of ways. Other family members also had an effect on the interviewee's high school sports participation.

\section{Discussion and conclusions}

In sum, we have presented a portrait of the experiences and influences that may have affected the experiences of these interviewees who participated in sports while in high school. We found that friendship and the opportunity to participate in a competitive activity were the main positive experiences the interviewees got from their high school sports participation. While the responses of fans and the experience of performing in public, and the experience of being on a team were also fairly common positive aspects of this participation, love of the sport was only occasionally mentioned and did not seem a central motivating factor for these students. Problems with coaching were prevalent for high school athletes, and were more problematic a negative factor than were injuries or conflicts with other activities. Family members, in particular parents, were the most important source of influence on students deciding to initiate or maintain their participation in a sport while in high school. They exerted their influence through investment of time, money and effort in introducing their children to sports and facilitating their participation. Serving as role models (especially when a parent was a former athlete them self, or when an elder sibling was an athlete) was another main way that families influenced the interviewee's participation. Finally, family members exerted influence, and sometimes control, over their children's sports participation by counseling against or at times forbidding sports activities that were perceived as risky or dangerous. Friends were the second most important influence reported. Friends invited interviewees to try new sports, or interviewees sometimes tried new sports just because a friend was on the team. Friends also provided a motivation for maintaining participation, because of the 
importance of the relationships with team members which developed as a result of their shared experiences.

There are several implications of these results for those interested in factors affecting sports participation among high school students. Understanding the positive factors that influence students' participation in high school sports may guide our efforts to create a more positive experience for high school athletes around the country. These results suggest that if high schools can provide coaches with better teaching and mentoring skills and techniques, the student athlete's experience of participating in the sport will be more enjoyable and more useful. A happy athlete is certainly more likely to continue participation than one who has had a negative experience with a coach. Encouraging sports participants to build friendships could also affect the long-term participation of athletes. Our findings also suggest that building community and team spirit in the form of fan attendance at sports events further reinforces all of the effort that athletes are putting into their sport. If a high school institution were looking to maintain or increase sport participation within its student body, encouraging fandom and the celebration of athletic events is a positive way to do so. Since many of the students described themselves as extremely competitive and motivated by competition, perhaps game-like competitive activities could be incorporated into more subject-matter courses at the high school level to tap into this competitiveness to drive academic motivation for these students.

Given the need to expand physical fitness on a national and global level, greater understanding of factors impacting sports participation will be useful to a wide range of stakeholders, including students, teachers and educational institutions, and policy makers. In this study we have contributed to the understanding of how students perceive their high school sports experience, including the positive and negative aspects of this experience. Limitations of the current study include the relative affluence of the student body at "Suburban University"; a comparison study with other universities could better access the experiences of students from a wider range of economic backgrounds. Such a comparison study would also provide a way of checking the generalizability of the results of our analysis. Further research should compare the perspectives of high school athletes with those who are not athletes, to see how their experiences and influences differ. Given our findings on the frequency of negative encounters with coaches during the high school years, a follow-up study involving interviews with coaches should be done to get their perspective on these experiences and relationships. 


\section{References}

Ahlberg, M., Mallett, C. J., \& Tinning, R. (2008). Developing autonomy supportive coaching behaviors: An action research approach to coach development. International Journal of Coaching Science, 2(2), 3-22.

Bailey, R. (2006). Physical education and sport in schools: A review of benefits and outcomes. Journal of School Health, 76, 397-401.

Berg, B. L. (1989). Qualitative research methods for the social sciences. Needham Heights, MA: Allyn \& Bacon.

Blumer, H. (1969). Symbolic interactionism: Perspective and method. New Jersey: Prentice-Hall.

Blumer, H. (1992). Society as symbolic interaction. In C. Clark \& H. Robboy (Eds.), Social interaction: Readings in sociology, 4th edition (pp. 24-28). New York: St. Martin's Press.

Charmaz, K. (2003). Grounded theory: Objectivist and constructivist methods. In N. K. Denzin \& Y. S. Lincoln (Eds.), Strategies of qualitative inquiry (pp. 249-291). Thousand Oaks, CA: Sage.

Charmaz, K. (2004). Grounded theory. In S. N. Hesse Biber \& P. Levy (Eds.), Approaches to qualitative research (pp. 496-521). Oxford, UK: Oxford University Press.

Coakley, J. (2006). The good father: Parental expectations and youth sports. Leisure Studies, 25(2), 153-162.

Crane, J. \& Temple, V. (2015). A systematic review of dropout from organized sport among children and youth. European Physical Education Review, 21(1), 114-131.

DeMeulenaere, E. (2010). Playing the game: Sports as a force for promoting improved academic performance for urban youth. Journal of Cultural Diversity 17(4), 127-135.

Glaser, B., \& Strauss, A. (1967). The discovery of grounded theory: Strategies for qualitative research. London, England: Wiedenfeld and Nicholson. 
Harris, P. C. (2014). The sports participation effect on educational attainment of Black males. Education and Urban Society, 46(5), 507-521.

Hassandra, M., Goudas, M., \& Chroni, S. (2003). Examining factors associated with intrinsic motivation in physical education: A qualitative approach. Psychology of Sport and Exercise, 4, 211-223.

Holt, N. L., Tink, L. N., Mandigo, J. L., \& Fox, K. R. (2008). Do youth learn life skills through their involvement in high school sport? Canadian Journal of Education, 31(2), 281-304.

Kondrič, M., Sindik, J., Furjan-Mandić, G. \& Schiefler, B. (2013). Participation motivation and student's physical activity among sports students in three countries. Journal of Sports Science and Medicine, 12, 10-18.

Knight, C. J. \& Holt, N. L. (2014). Parenting in youth tennis: Understanding and enhancing children's experiences. Psychology of Sport and Exercise, 15, 155-164.

Lacroix, M. C., \& Trudel, P. (2008). High school coaches' characteristics and their perspectives on the purpose of school sport participation. International Journal of Coaching Science, 2(2), 23-42.

Marsh, H. W. \& Kleitman, S. (2003). School athletic participation: Mostly gain with little pain. Journal of Sport and Exercise Psychology, 25, 205-228.

Morse, J. M. (1994). Emerging from the data: The cognitive processes of analysis in qualitative inquiry. In J. M. Morse (Ed.), Critical issues in qualitative research methods (pp. 23-43). Thousand Oaks, CA: Sage.

Pummell, B., Harwood, C. \& Lavallee, D. (2007). Jumping to the next level: A qualitative examination of within-career transition in adolescent event riders. Psychology of Sport and Exercise, 9(4), 427-447.

Rubin, H. J. \& Rubin, I. S. (2005). Qualitative interviewing: The art of hearing data. Thousand Oaks, CA: Sage.

Russell, W. D. \& Limle, A. N. (2013). The relationship between youth sport specialization and involvement in sport and physical activity in young adulthood. Journal of Sport Behavior, 36(1), 82-98.

Shulman, J. L. \& Bowen, W. G. (2001). The game of life: College sports and educational values. Princeton, NW: Princeton University Press. 
Vazou, S., Ntoumanis, N., \& Duda, J. L. (2005). Peer motivational climate in youth sport: A qualitative inquiry. Psychology of Sport and Exercise, 6, 497-516.

\section{Appendix: Interview Guide Questions}

1. Type of Sport and Level of Participation

a. What sport or sports did you play in High School? What level of sport did you play in High School? (If they played more than one sport, which sport did they like best and why?)

b. How long have you been participating in the sport?

c. How often do you participate in the sport?

2. Questions for Subjects Who Were on High School Teams

a. Describe your experience participating in this sport, both positive and negative.

b. How did your academic responsibilities and other activities affect your decision regarding participation?

c. Were you recruited coming out of high school?

3. Questions for All Subjects (Formal and/or Informal Sports Participants)

a. What part did you enjoy most about high school sports?

b. What were your largest influences in beginning to play sports?

i. How did your friends impact your sports participation in high school? Didyour friendship network revolve around the teams you played on? ii. How did your family impact your sports participation in high school? iii. How important were sports in your high school/ hometown? iv. How good was your high school sports team? v. How has your coach impacted your participation in your sport? (positive or negative)

vi. How competitive do you consider yourself when playing sports? 
Angela Cora GARCIA, $\mathrm{PhD}$ is an associate professor of sociology with a secondary appointment in global studies at Bentley University in Waltham, Massachusetts (USA). She does qualitative research on a range of subjects, including studies of interaction in emergency phone calls, mediation sessions, and computer-mediated communication, and interview-based studies of animal rescue organizations and leisure activities. She teaches courses in the Sociology of Sports, Conversation Analysis, Cross Cultural Communication, and Animals in Society.

\section{Corresponding address:}

Angela Cora Garcia

Department of Sociology

Bentley University

175 Forest Street

Waltham, Massachusetts, 02452

U.S.A.

E-mail: agarcia@bentley.edu 